\title{
A questão da desigualdade territorial municipal no Espírito Santo face à pandemia do coronavirus e a importância da existência de um Estado de bem estar social em defesa da sociedade.
}

La question de l'inégalité territoriale des communes de l'état de l'Espírito Santo au Brésil face à la pandémie de coronavirus et l'importance d'un État social en défense de la société.

The issue of municipal territorial inequality in Espirito Santo in the face of the coronavirus pandemic and the importance of the existence of a welfare state in defense of society

La cuestión de la desigualdad territorial municipal en Espírito Santo frente a la pandemia de coronavirus y la importancia de la existencia de un Estado de bienestar en defensa de la sociedad.

\section{Cláudio Luiz Zanotelli and Ednelson Mariano Dota}

\section{(2) OpenEdition}

\section{Journals}

Electronic version

URL: http://journals.openedition.org/espacoeconomia/10207

DOI: 10.4000/espacoeconomia.10207

ISSN: 2317-7837

\section{Publisher}

Núcleo de Pesquisa Espaço \& Economia

Electronic reference

Cláudio Luiz Zanotelli and Ednelson Mariano Dota, «A questão da desigualdade territorial municipal no Espírito Santo face à pandemia do coronavirus e a importância da existência de um Estado de bem estar social em defesa da sociedade. », Espaço e Economia [Online], 17 | 2020, Online since 06 April 2020, connection on 21 April 2020. URL : http://journals.openedition.org/espacoeconomia/ 10207 ; DOI : https://doi.org/10.4000/espacoeconomia.10207 


\section{A questão da desigualdade territorial municipal no Espírito Santo face à pandemia do coronavirus e a importância da existência de um Estado de bem estar social em defesa da sociedade.}

La question de l'inégalité territoriale des communes de l'état de l'Espírito Santo au Brésil face à la pandémie de coronavirus et l'importance d'un État social en défense de la société.

The issue of municipal territorial inequality in Espirito Santo in the face of the coronavirus pandemic and the importance of the existence of a welfare state in defense of society

La cuestión de la desigualdad territorial municipal en Espírito Santo frente a la pandemia de coronavirus y la importancia de la existencia de un Estado de bienestar en defensa de la sociedad.

Cláudio Luiz Zanotelli and Ednelson Mariano Dota

\section{Introdução}

Neste curto texto pretendemos indicar a situação, ou a posição geográfica daqueles - a população com mais de 60 anos - que, segundo as pesquisas recentes, estão entre os mais suscetíveis a terem complicações de saúde e mesmo virem a falecer por causa da contaminação do novo Coronavirus (COVID 19). Inicialmente, no artigo, vamos 
apresentar a distribuição desta população com mais de 60 anos no território e, brevemente, relatamos a situação da contaminação do vírus no Espírito Santo e as projeções que o Estado efetuou sobre a difusão do mesmo. Notaremos, deste modo, a sua concentração metropolitana e em três cidades médias ao norte e ao sul do estado. Concluiremos nos interrogando sobre os cuidados necessários neste momento com aqueles que se encontram em territórios interioranos por enquanto com pouco ou nenhum caso confirmado, mas sujeitos a estas contaminações e desprovidos de infraestrutura médica de atendimento para os casos graves, revelando, deste modo, uma fratura territorial nos serviços médicos de complexidade.

2 Uma questão que atravessa todo o texto implícita ou explicitamente - o artigo busca indicar questões empíricas emergenciais e questionar a infraestrutura de saúde pública destinada àqueles que necessitam de cuidados em função das fraturas territoriais - é aquela da importância do Estado de Bem Estar Social. Defender não o Estado em geral e ainda menos a casta no poder, mas as funções sociais que são também funções universais realizadas pelo Estado na nossa sociedade e que são, sobretudo, o resultado de conquistas sociais das gerações precedentes. Como escreve Pierre Bourdieu "Se trata de defender a 'mão esquerda' do Estado social que assegure o funcionamento dos serviços públicos e uma certa redistribuição dos recursos." (BOURDIEU citado por LAVAL, 2018, p. 67). E ele continua "... este Estado social é o único a se contrapor aos mecanismos implacáveis da economia abandonada à ela mesma." (Idem). Acrescentaríamos que isto não significa, por um lado, não reconhecer o papel de todos os movimentos sociais nas conquistas coletivas e comuns, ao contrário, e não significa, por outro lado, defender um Estado autoritário e que penalize e controle seu povo e as populações dominadas aproveitando do momento para realizar uma maior repressão se fundando na "teoria do choque" bem descrita por Naomi Klein (21/03/2020). Este é, também, o momento de colocar a questão da responsabilidade do neoliberalismo no estado de coisas atuais e de sua penetração no Estado profundo, nas classes dominantes e no conjunto da sociedade. O neoliberalismo acelerou a predação e despossessão de territórios tradicionais e a destruição dos habitats naturais colocando em risco milhões de espécies e acelerando o surgimento de pandemias a partir de micróbios que são inofensivos aos animais, mas que, com a destruição das florestas, a urbanização e a industrialização sem limites, tiveram o caminho livre para chegarem ao corpo humano e se adaptar (SHAH, 2020). Esta situação, bem como a criação em massa de animais para abate, facilita a passagem de vírus relativamente inofensivos aos animais para os seres humanos (como foi o HIV, o Ebola, a "gripe aviária", a Zika e como é, aparentemente, o caso do Covid-19 e outros nas quatro últimas décadas). Esta presença quase universal do neoliberalismo - do discurso à ação dos Estados independentemente do grau de desenvolvimento, utilizando-se do termo "austeridade" como palavra de ordem - e de suas contradições insuperáveis que fazem pagar às classes dominadas o pesado preço de sua acumulação e predação em espiral infindáveis, também está na origem da proliferação do vírus com a circulação Just in time da qual depende o capitalismo global, bem como está na base da dependência total das economias nacionais do mercado financeiro globalizado (HARVEY, 2011). Por fim, o estado lamentável da saúde pública como parte das ações neoliberais de redução do Estado, aprofundado desde a queda dos investimentos a partir de 2015 e tendo tido acentuado desmonte nos últimos quatro anos pelos governos de Temer e de Bolsonaro - não obstante todo o esforço dos servidores lotados na ponta do SUS (Sistema Único de Saúde) e os elogios internacionais 
ao sistema - é o coroamento deste vírus globalizado neoliberal em seu encontro explosivo com o Covid-19.

\section{O contexto da presença dos idosos no Espírito Santo face ao Covid-19}

3 Considerando que a demanda por hospitalização e cuidados críticos varia consideravelmente conforme a idade (FERGUSON et al., 2020), vale refletir sobre os possíveis impactos da distribuição espacial das pessoas idosas ${ }^{1}$. Além disso, entre os níveis político-administrativos, os municípios têm papel decisivo no estabelecimento de atendimento primário à saúde, ao mesmo tempo em que a distribuição de infraestrutura hospitalar de média e alta complexidade tem outra lógica de organização que não é a municipal e se concentra em cidades da região metropolitana ou em poucas cidades de porte médio.

4 Nesse contexto, uma maior concentração de pessoas idosas em determinadas porções do território pode sugerir a necessidades de medidas específicas, que podem variar a depender do andamento das transmissões. De todo modo, o envelhecimento brasileiro, mais recente do que os países europeus, está em processo de aceleração, sendo que projeta-se que pouco mais de $14,3 \%$ da população brasileira tenha 60 anos ou mais agora em 2020 (Gráfico 1). Essas proporções são ligeiramente distintas se considerarmos o Sudeste em seu conjunto (16,1\%), com o Espírito Santo vindo logo abaixo $(14,7 \%){ }^{2}$

5 Mais importante do que essa diferença, que é relativamente homogênea para todos os estados do país, é o crescimento no volume de idosos observado desde o ano 1970 até 2020: o Brasil observou aumento dessa população em 25,4 milhões, enquanto o Sudeste em 12,0 milhões, dos quais 520 mil residentes no Espírito Santo, que teria em 2020 aproximadamente 592 mil idosos $^{3}$. O envelhecimento, nesse sentido, não se refere a indivíduos ou gerações, mas as mudanças na estrutura etária da população, sendo, portanto, influenciado por fatores econômicos, sociais, científicos e culturais, além dos biológicos (CARVALHO; GARCIA, 2003). 
Gráfico 1. Proporção de idosos na população residente e projeção para 2020. Brasil, Sudeste e Espírito Santo, 1970 a 2020.

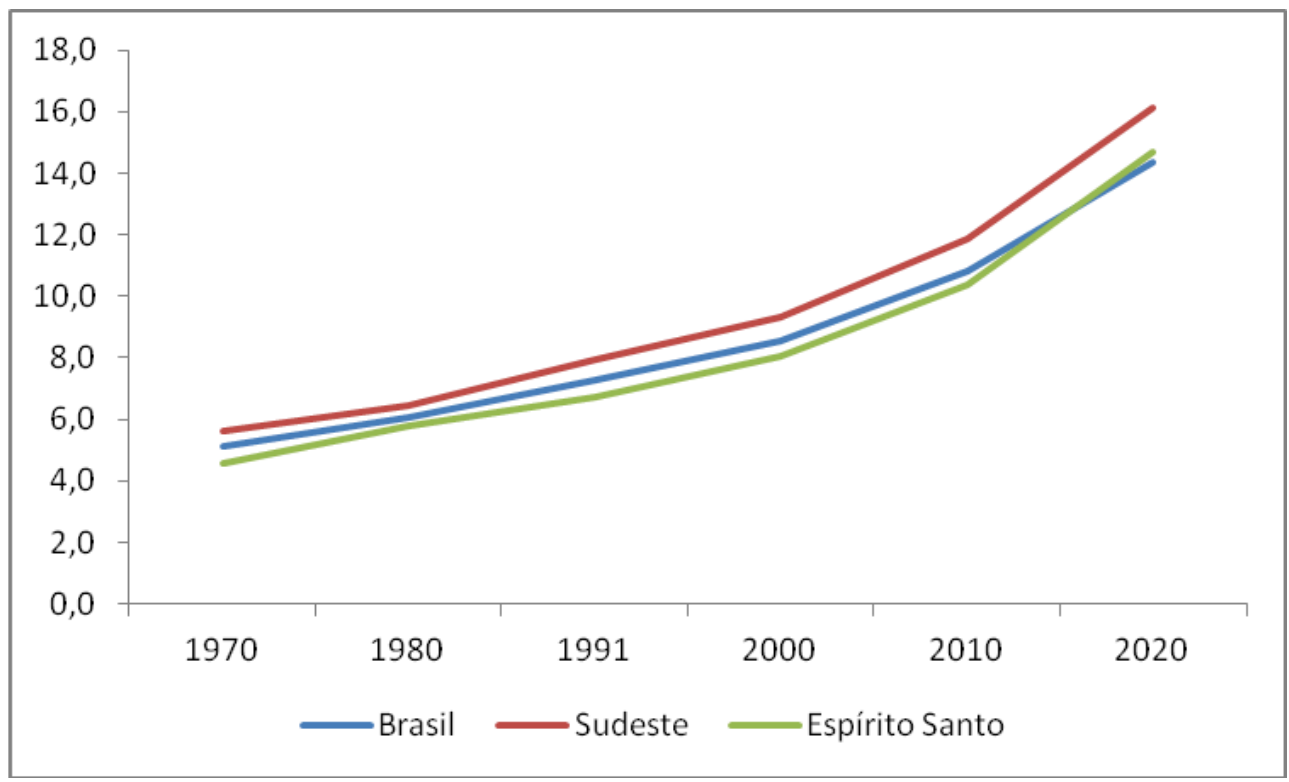

Fonte: IBGE. Censo Demográfico de 1970, 1980, 1991, 2000, 2010 e projeção para 2020

6 O envelhecimento observado numa perspectiva temporal e espacial conjuntamente evidencia o afloramento das desigualdades territoriais nesses últimos 50 anos. Conforme demonstra a Figura 1, em 1970, os municípios do Espírito Santo apresentavam pouca variação entre si em relação ao índice de envelhecimento. Nos períodos subsequentes as disparidades começam a ganhar destaque, chegando em $2010^{4}$ com diferenciações que refletem as desigualdades na distribuição da dinâmica econômica entre as diversas porções do território.

Destacamos no mapa de 2010 uma faixa com menor índice desde alguns municípios da Região Metropolitana da Grande Vitória (RMGV) até a divisa com a Bahia, incluindo toda a região que denominamos litoral norte e que tem sido uma das mais beneficiadas por investimentos industriais e do setor de petróleo e gás do estado (ZANOTELLI et al., 2019). À oeste, áreas com índice de envelhecimento maior, com destaque para a região central do estado. Nestas estão municípios com economia menos dinâmica, com predominância do setor primário e com municípios que há décadas vem apresentando evasão migratória (DOTA, 2019). 
Figura 1. Índice de envelhecimento. Municípios do Espírito Santo, 1970 a $2010^{5}$.
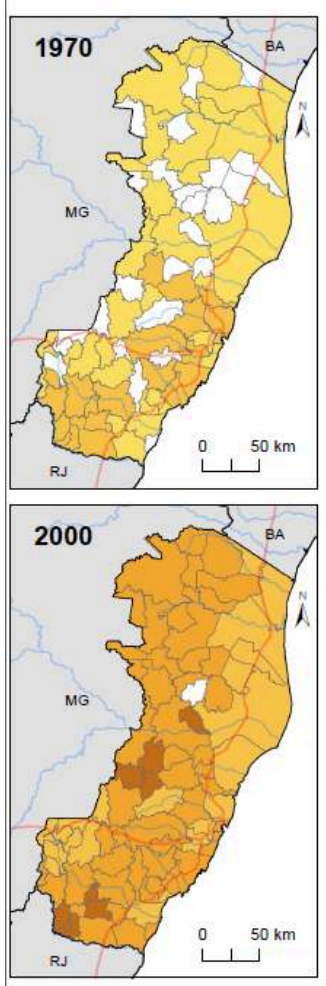
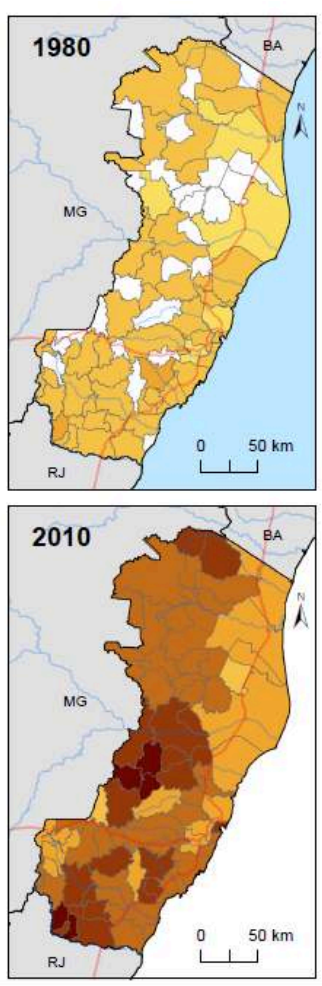
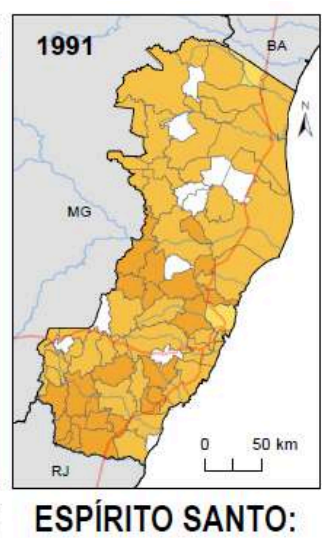

Indice de Envelhecimento

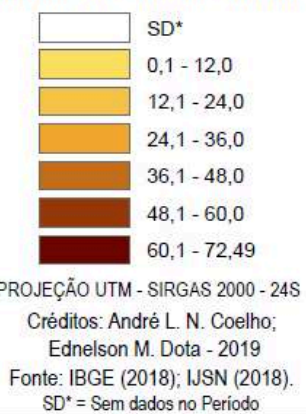

8 A migração, nesse sentido, desempenha um papel importante para o envelhecimento ou rejuvenescimento dos municípios, já que a seletividade por idade, que é inerente aos movimentos, culminam geralmente em envelhecimento mais rápido do município que perde população, e do rejuvenescimento daquele que ganha, sobretudo nas trocas interior - grandes cidades. Nas trocas locais das grandes aglomerações há outros elementos que devem ser levados em conta e que modificam essa relação.

Em nível municipal, a elaboração de estratégias que levem em conta o nível de envelhecimento dos municípios deve separar os municípios em dois grupos: o primeiro, com maior número de municípios, mas com menor população, são aqueles com menor interdependência e fluxos cotidianos, conformando a grande maioria do interior. Nestes o índice de envelhecimento se coloca como variável fundamental para ser analisada junto à própria disponibilidade de infraestrutura para atendimento. 0 segundo grupo se refere aos municípios pertencentes às grandes aglomerações ou com forte integração com vizinhos. Nestes, os níveis de envelhecimento são importantes, mas devem ser relativizados, já que a mobilidade cotidiana para trabalho e estudo borra as diferenças existentes entre eles.

10 Como exemplo, na RMGV a capital, Vitória, apresentava em 2010 aproximadamente $10,4 \%$ de idosos em sua população, enquanto Serra tinha apenas $6,3 \%$. Por outro lado, somente com vistas ao trabalho, saiam de Serra diariamente para Vitória mais de $38 \mathrm{mil}$ pessoas, o que exemplifica a necessidade de um planejamento conjunto que considere a proporção de idosos, mas principalmente a dinâmica cotidiana de circulação que torna as regiões metropolitanas uma só grande cidade.

11 Assim, quando pensamos na proporção dos idosos pelos municípios, vê-se que ela é relativamente alta nos municípios interioranos: variava de 6,0\% a 14,0\% em 2010, com média de 10,1\%, numa dinâmica espacial semelhante ao que se observa na Figura 1. 
Tendo o estado aumentado sua população idosa em 4,3 pontos percentuais entre $2010 \mathrm{e}$ 2020 (de 10,4\% para 14,7\%) e, pressupondo a continuidade dos movimentos migratórios como se observou ao longo da década de 2000 , estima-se que o interior tenha aumentado ligeiramente a diferença na proporção de pessoas idosas em relação à RMGV, onde variava de $6,3 \%$ a $10,4 \%$, com média de $8,3 \%$. Isso, associado às insuficiências de hospitais em muitos destes municípios poderá colocar problemas para o atendimento das populações vulneráveis desta área.

Deste modo, não somente é importante ter uma infraestrutura de atendimento local, mas também serviços de remoção de pessoas que necessitam de cuidados dos pequenos municípios para os centros maiores, como o indicou o Presidente do Conselho Regional de Medicina do Espírito Santo (Gazeta on line, 21/03/2020).

13 Apesar da evolução cotidiana dos casos e da instabilidade dos dados, no dia 23 de março se contavam 29 casos de coronavirus no Espírito Santo, a imensa maioria (26 casos) na RMGV, em particular em Vitória com 13 e Vila Velha com 12 casos e em Cariacica (1 caso). Os três outros casos se localizavam na capital regional, Cachoeiro do Itapemirim, localizada no sul do estado, e no centro subregional de Linhares (2 casos) ao norte do estado (Cf. Mapa do G1, 23/03/2020). Porém os casos suspeitos, e que restam a ser confirmados, representam 696 casos em 42 dos 78 municípios do estado. Mais uma vez, como era de se esperar, são os municípios da RMGV ( $80 \%$ dos casos) e os dois municípios citados anteriormente, juntamente com outro município que é um centro subregional (Colatina) - que têm ao todo $8 \%$ dos casos - que detêm a imensa maioria dos casos sob investigação. Nos municípios interioranos, onde o índice de envelhecimento é mais elevado, os casos suspeitos são pouco numerosos. Portanto é nos lugares de maior concentração de população, de maior concentração industrial e de serviços, e em consequência de maior urbanização e de maior circulação de pessoas e de mercadorias onde a contaminação e o risco de difusão são mais elevados. Mas nestes lugares é também onde há mais infraestruturas e equipamentos de saúde. Assim, mesmo se no interior, à exclusão das cidades médias citadas, o número de casos suspeitos é pouco elevado, bem como nulo os casos confirmados até aqui, estes municípios são os mais expostos à necessidade de atendimento de média e alta complexidade. Por isto mesmo, a importância de não se deixar alastrar a epidemia para estes lugares destituídos de hospitais equipados com UTIs.

14 A população estimada do estado em 2020 é de 4,064 milhões de habitantes e, como vimos, aqueles com 60 anos ou mais somam aproximadamente 592 mil pessoas. Em função destes dados e do que se pode deduzir provisoriamente dos casos internacionais, cada um com sua particularidade, donde há dificuldade em realizar deduções simples sobre taxas de contaminação e de casos graves e de mortalidade, foram feitas previsões pelos responsáveis estaduais da saúde pública - estas previsões são puramente circunstanciais e os dados mudam de hora em hora - indicando que o Espírito Santo teria em 90 dias cerca de 4 mil casos de contaminação por coronavirus (A Gazeta online, $21 / 03 / 2020$ ). Destes, $80 \%$ seriam casos leves (3.200 casos) e $20 \%$ casos graves ( 800 pessoas) e dentre eles os casos críticos atingiriam de $3 \%$ a $5 \%$ (de 24 a 40 casos). No entanto, outros especialistas invocados pelo jornal citado trabalham com a probabilidade de até 200 casos graves e de que um número significativo deles possa falecer. Diante destes fatos, o governo do estado previu e está preparando 200 leitos em UTI (Idem). Mas, claro, estas são informações factuais e sujeitas à confirmação. 0 governo "comunica" e procura dar uma imagem competente e preventiva de sua 
"gestão". O que vemos na prática e o que veremos provavelmente com o desenvolvimento e extensão das contaminações são hospitais e centros de atendimento à saúde básica incapazes de atender à demanda e/ou sem os equipamentos e materiais necessários. Em alguns deles já faltam máscaras para os profissionais de saúde e não sabemos se no estado o número de "ventiladores" para assistência de emergência para os casos de insuficiências respiratórias serão suficientes.

Assim, por paradoxal que possa parecer e por mais limitado que sejam, por enquanto, os casos no Espírito Santo, eles nos revelam que a concentração das atividades econômicas e da circulação de pessoas e de mercadorias - globalização e neoliberalismo contribuindo para este estado de coisas - favorecem a circulação do vírus (Cf. CASTILHO, 2020), como era de se esperar, e também nestes lugares é onde temos maior infraestrutura de saúde, por isso o interior se revela por enquanto um lugar relativamente livre da proliferação do vírus, que em um momento ou outro ali deverá chegar. Porém, se uma contaminação rápida atinge o interior, os seus habitantes mais idosos e mais frágeis correm o sério risco de ficarem desamparados face à demanda crescente da Região Metropolitana e das cidades médias. Esta situação é reflexo da forma de desenvolvimento concentrador e da forma de distribuição dos equipamentos e infraestrutura de saúde também concentradora, revelando uma fratura territorial entre o interior e a zona metropolitana e as cidades regionais. Fratura que, diga-se de passagem, como também têm indicado vários artigos, atingirá os bairros populares, as periferias e as favelas metropolitanas e não metropolitanas (BARBOSA, 2020).

Em função do que indicamos, notamos questões centrais para o cuidado dos mais frágeis, mais expostos e mais idosos e, como nestes momentos o território revela estas fraturas territoriais, volta-se a demonstrar a centralidade do Estado como forma de mudar este "estado de coisas" e de aprofundar a proteção social. Ao mesmo tempo, constatamos as contradições flagrantes das práticas neoliberais que atacam e desmontam o Estado e, quando algo de extraordinário ocorre, pedem mais Estado para proteger o setor financeiro e o alto patronato. Nesse sentido, as intervenções do Estado devem ser prioritariamente para garantir a igualdade e equidade sócio-espacial, como em alguns exemplos pelo mundo atualmente, coisa que não acontece neste momento no Brasil, apesar das iniciativas de muitos governadores e prefeitos. A base sobre a qual se dão as iniciativas é extremamente desigual, pois nos últimos anos se desmontou gradualmente as políticas sociais, de cuidados à saúde e de solidariedade territorial. E, por fim, não há uma coordenação nacional e há de parte dos poderes nacionais constituídos - aproveitando do "choque" e da desorganização sociais - um descaso e um ataque em regra aos direitos dos trabalhadores e dos cidadãos comuns a fim de proteger predominantemente aqueles das grandes empresas e do setor financeiro. Isto revela, sobretudo, a contaminação do Estado em geral pelas práticas neoliberais e, neste momento de medo generalizado da morte que nos espreita, evidencia ainda mais a necessidade da reflexão acerca do papel do Estado, das ações e políticas que, apesar do discurso contrário, aprofundam as diferenças e desigualdades já escandalosas no Brasil e no mundo. 


\section{BIBLIOGRAPHY}

A Gazeta online. Coronavirus: mais vulneráveis idosos representam $16 \%$ da população do Espírito Santo. Acessado em 23/03/2020. Disponível em https://www.agazeta.com.br/es/gv/coronavirusmais-vulneraveis-idosos-representam-16-da-populacao-do-es-0320

BARBOSA, Jorge. Uma quarentena de direitos para as favelas e as periferias! Texto disponível nas redes sociais, 20 de março de 2020.

CARVALHO, José Alberto Magno de; GARCIA, Ricardo Alexandrino. $O$ envelhecimento da população brasileira: um enfoque demográfico. Cadernos de Saúde Pública, v. 19, n. 3, p. 725-733, 2003.

CASTILHO, Denis. Um vírus com DNA da globalização: o espectro da perversidade, Pragmatismo político, 23/03/2020.

DOTA, Ednelson M.. Oportunidades de trabalho e a migração rural-urbana no Espírito Santo. Revista Rural \& Urbano, v. 04, p. 37-56, 2019.

FERGUSON, Neil M. et al. Impact of non-pharmaceutical interventions (NPIs) to reduce COVID-19 mortality and healthcare demand. Imperial College London, 2020.

G1. Mapa do coronavírus no Brasil. Acessado em 24/03/2020. Disponível em https:// especiais.g1.globo.com/bemestar/coronavirus/mapa-coronavirus/? _ga $=2.172053216 .2111506115 .1585047628-1221903934.1585047625$

HARVEY, David. O enigma do capital e as crises do capitalismo. São Paulo: Boitempo, 2011.

IBGE - Instituto Brasileiro de Geografia e Estatísticas. Projeções da população brasileira por estado e por faixa etária de 2010 a 2060, 2018.

KLEIN, Naomi. Coronavírus: como vencer o capitalismo que se abastece de desastres? The Intercept, 21 de março de 2020.

LAVAL, Christian. Foucault, Bourdieu et la question néolibérale. Paris : La Découverte, 2018.

SHAH, Sonia. Contra a pandemia a ecologia. Le Monde Diplomatique, março de 2020.

ZANOTELLI, Claudio L. ; DOTA, Ednelson M. ; FERREIRA, Francismar C.; RODRIGUES, Rennan M. Urban-regional oil basin: the coastal area of Espírito Santo associated with the Rio de Janeiro State - Brazil. CONFINS (PARIS), v. 1, p. 1-20, 2019.

\section{NOTES}

1. Consideramos idosas as pessoas com 60 anos ou mais de idade.

2. $\mathrm{Na}$ análise do contexto do Espírito Santo utilizamos dados dos recenseamentos brasileiros de 1970 a 2010, tanto para a visão do conjunto do estado quanto da análise em nível municipal, além da Projeção de população por sexo e idade de 2018 do IBGE, objetivando mostrar o aceleramento do envelhecimento pós-2010.

3. O Jornal online A Gazeta de 21/03/2020 indica que o Espírito Santo teria em 2019 16\% de sua população composta de idosos, apresentando como fonte o IBGE, porém as projeções do IBGE (2018) disponíveis apresentam 14,4\% de população idosa para o estado em 2020.

4. Não dispomos de projeções da população por faixa etária por município para 2020.

5. Os municípios "sem dados" são aqueles emancipados após o período de referência dos dados. 


\section{ABSTRACTS}

The article seeks to indicate emergency empirical issues related to Coronavirus-19 and interrogate the public health infrastructure destiny to the ones that needs to require care due to territorial fractures and indicate the importance of Welfare State. Defends not the State in general and even less the caste in power, but the social functions that are also universal functions performed by the State in our society and which are, above all, the result of social achievements of previous generations. Based on this assumption, the geographical position of the population over 60 years of age is indicated. Firstly, in the article, it present the distribution of this population in the territory and, briefly, the situation of contamination of the virus in Espírito Santo and the projections that the State made about its dissemination are reported. It is concluded by questioning the necessary care for those subjected to virus contamination that are in interior territories devoid of medical care infrastructure for severe cases, thus revealing a fracture in complex medical services.

O artigo busca indicar questões empíricas emergenciais ligadas ao Coronavirus-19 e interrogar a infraestrutura de saúde pública destinada àqueles que necessitam de cuidados em função das fraturas territoriais e indica a importância do Estado de Bem Estar Social. Defende não o Estado em geral e ainda menos a casta no poder, mas as funções sociais que são também funções universais realizadas pelo Estado na nossa sociedade e que são, sobretudo, o resultado de conquistas sociais das gerações precedentes. Partindo desse pressuposto indica-se a posição geográfica da população com mais de 60 anos. Inicialmente, no artigo, apresenta-se a distribuição desta população no território e, brevemente, relata-se a situação da contaminação do vírus no Espírito Santo e as projeções que o Estado efetuou sobre a difusão do mesmo. Conclui-se interrogando os cuidados necessários com aqueles sujeitos a contaminações pelo vírus que se encontram em territórios interioranos desprovidos de infraestrutura médica de atendimento para os casos graves, revelando, deste modo, uma fratura territorial nos serviços médicos de complexidade.

L'article cherche à reveler des problèmes d'urgence sanitaire liées au Coronavirus-19 et à remettre en question l'infrastructure de santé publique destinnée a ceux qui ont besoin de soins en raison de fractures territoriales et indique l'importance de l'action de l'État en defense de la société. Il défend non pas l'État en général et encore moins la caste au pouvoir, mais les fonctions sociales qui sont aussi des fonctions universelles exercées par l'État dans notre société et qui sont, avant tout, le résultat des conquêtes sociales des générations précédentes. Sur la base de cette hypothèse, il centre son analyse sur la population de plus de 60 ans et, dans un premier temps, présente la répartition de cette population sur le territoire. En suite, brièvement, rapporte la situation de la contamination du virus à Espírito Santo et les projections que l'État a faites sur sa propagation. Conclu en s'interrogeant sur les soins nécessaires pour ceux qui habitente les communes rurales dépourvus d'infrastructures médicales pour prendre en charge les cas les plus graves, révélant ainsi une fracture territoriale.

El artículo busca indicar cuestiones empíricos de emergencia relacionados con Coronavirus-19 e interrogar la infraestructura de salud pública para aquellos que necesitan atención debido a fracturas territoriales e indica la importancia del Estado de bienestar. Defiende no al Estado en general y menos aún a la casta de poder, sino a las funciones sociales que también son funciones universales desempeñadas por el Estado en nuestra sociedad y que son, sobre todo, el resultado de las conquistas sociales de generaciones anteriores. En base a esta suposición, se indica la posición geográfica de la población mayor de 60 años. Inicialmente, en el artículo, se presenta la 
distribución de esta población en el territorio y, brevemente, se informa la situación de la contaminación del virus en Espírito Santo y las proyecciones que hizo el Estado sobre su difusión. Concluye cuestionando la atención necesaria con aquellos sujetos a la contaminación por el virus que se encuentran en territorios ubicados en el interior que carecen de una infraestructura médica para casos graves, revelando así una fractura territorial en servicios médicos complejos.

\section{INDEX}

Keywords: Espírito Santo; Brazil; coronavirus; territorial inequality; seniors.

Palavras-chave: Espírito Santo, Brasil, Coronavirus, Desigualdade territorial, Idosos

Palabras claves: Espírito Santo, Brasil, Coronavirus, Desigualdad territorial, Ancianos

Mots-clés: Espírito Santo, Brésil, Coronavirus, Inégalité territoriale, Personnes âgées

\section{AUTHORS}

CLÁUDIO LUIZ ZANOTELLI

clzanotelli@yahoo.com.br

EDNELSON MARIANO DOTA

ednelson.dota@ufes.br 